\title{
Quantitative $x$ ray microanalysis of pulmonary mineral particles in a patient with pneumoconiosis and two primary lung tumours
}

\author{
S ANTTILA, ${ }^{1}$ S SUTINEN, ${ }^{1}$ P PÄÄKKÖ, ${ }^{1}$ T ALAPIETI, ${ }^{2}$ R PEURA,${ }^{3}$ AND S J SIVONEN ${ }^{3}$ \\ From the Departments of Pathology ${ }^{1}$ and Geology ${ }^{2}$ and Institute of Electron Optics, ${ }^{3}$ University of Oulu, \\ Oulu, Finland
}

\begin{abstract}
The right upper lung lobe of a 74 year old man was resected for a central tumour. Two primary cancers were found; a central small cell carcinoma and a peripheral squamous cell carcinoma. In addition, the peripheral lung tissue showed generalised peribronchiolar fibrosis extending from the non-respiratory bronchioles to the level of the alveolar ducts. Abundant asbestos bodies and large amounts of black dust were seen around the bronchioles. Pulmonary mineral particles were studied by quantitative energy dispersive $x$ ray microanalysis (EDS) using scanning transmission electron microscopy (STEM). The $x$ ray spectra for mineral particles were measured in thin sections, and the characteristic peak intensities of the elements were converted to weight fractions (in oxides). The results enabled the minerals present to be identified and their presence confirmed by calculating the mineral formula. These originated from nine natural minerals, anthophyllite and chrysotile asbestos, talc, and quartz, feldspars, and muscovite, which are components of sand, and also from two artificial mullites used in fire clay. The exposure history of the patient explained the most likely origins of the minerals detected. The patient had been a mason for 23 years, repairing and demolishing stoves and fireplaces and using asbestos for insulation work.
\end{abstract}

To diagnose a pneumoconiosis and elucidate its aetiology it is necessary to determine the type and quantity of the inorganic dust present in the lung tissue. It is possible to show ferruginous bodies by light microscopy and even to distinguish true asbestos bodies from those containing sheet silicate or carbon cores, ${ }^{1}$ but the rest of the inorganic dust is seen as a black pigment, or as birefringent crystals in polarising light, and no conclusions can usually be drawn concerning the types of mineral concerned. The morphology of a particle under electron microscopy cannot usually be used for reliable identification either, although chrysotile asbestos is sometimes recognisable because of its tubular shape. ${ }^{2}$ The value of electron microdifraction is similarly limited largely to the identification of varieties of asbestos. ${ }^{23}$

Received 6 March 1984

Accepted 2 April 1984
Energy dispersive spectroscopy (EDS) combined with transmission or scanning electron microscopy enables sodium (atomic number 11) and heavier elements to be determined from individual particles. For the precise quantitative microanalysis of small particles, Cliff and Lorimer developed a concentration ratio method by which the measured $x$ ray intensities of the elements may be simply converted to weight percentages. ${ }^{4}$ This procedure has been shown to be reasonably accurate for the analysis of thin metal foils. The same method has since been used successfully for analysing metal and mineral specimens (see the work of Pooley, ${ }^{5}$ Champness et $a l,{ }^{2}$ Lorimer, ${ }^{6}$ and Malami and Grassenbauer ${ }^{7}$ ) but to our knowledge has not been used previously to analyse pulmonary mineral particles in situ. In the work reported here the method of Cliff and Lorimer ${ }^{4}$ has been applied to the analysis of inorganic dust particles in an apparently pneumoconiotic lung specimen resected for cancer. 


\section{Method}

Tissue for light and electron microscopy was taken from a surgical specimen consisting of the resected upper lobe of the right lung fixed intrabronchially with hyperosmolaric formalin. ${ }^{8}$ The specimens for light microscopy were embedded in paraffin, cut into sections of $5 \mu \mathrm{m}$ and stained with haematoxylin and eosin, van Gieson's and Pearl's iron stains, and the silver nitrate stain of Grimelius. ${ }^{9}$ The severity and extent of peribronchiolar fibrosis were estimated according to the asbestos grading scheme of Craighead et al.$^{10}$ The specimens for electron microscopy were postfixed in osmium tetroxide, dehydrated in alcohol, and embedded in an LX-112 plastic medium. Semithin and thin sections were cut on an LKB Ultrotome III ultramicrotome. The former were stained with toluidine blue and the latter with uranyl acetate. The semithin sections were checked by light microscopy, and tissue blocks containing dust were selected for thin sections of $0 \cdot 1 \mu \mathrm{m}$. The sections were placed on copper grids of 200 mesh.

The samples containing dust were examined using a JEOL $100 \mathrm{CX}$ scanning transmission electron microscope (STEM) fitted with a PGT 1000 energy dispersive spectrometer. Transmission electron microscopy and all the microanalyses were performed at an accelerating voltage of $80 \mathrm{kV}$. The other analysis parameters were: beam current about $0 \cdot 1 \mathrm{nA}$, specimen tilt $30^{\circ}$, and measuring time $200 \mathrm{~s}$. The $x$ ray spectra for the dust particles were measured by overscanning with a small raster using the STEM operating mode of the microscope.

According to Cliff and Lorimer, ${ }^{4}$ the characteristic $x$ ray intensity ratio, $I_{A} / I_{B}$, of two elements, $A$ and $B$, may be related to the weight fractions, $C_{A}$ and $C_{B}$, by $C_{A} / C_{B}=k_{A B}\left(I_{A} / I_{B}\right)$, in which $k_{A B}$ is a relative sensitivity factor, the "Cliff-Lorimer" factor, which varies with the accelerating voltage but is independent of the sample thickness and composition, provided that the two intensities are measured simultaneously and the thin foil criterion-no absorption and no fluorescence-is satisfied. The constant $\mathrm{k}_{\mathrm{AB}}$ can be determined experimentally from thin standards or by calculation from a theoretical equation. Both procedures were tried, but analyses of a few minerals of known composition showed that the measured values were considerably more accurate, especially for sodium, magnesium, and aluminum, for which the computed $k_{A B}$ values were too low-a tendency reported in many papers. $^{61}$ The experimental values for $\mathrm{k}_{\mathrm{AB}}$ were determined from the EDS spectra of six metal sulphates using the procedure described by Barbi. ${ }^{12}$

The conversion of the measured EDS spectrum for a dust particle to the composition and formula of the mineral concerned included the following steps:

(1) background subtraction using a linear method,

(2) use of the Cliff-Lorimer equation to convert the characteristic peak intensities of the elements analysed to the stoichiometric oxides to give a total of $100 \%$, and (3) use of these results for the preliminary identification of the dust particle in question. The identification was confirmed by calculating the mineral formula.

\section{Case report}

The patient was a 74 year old man who had smoked for 50 years. He had worked as a mason for 23 years, repairing and demolishing stoves and fireplaces. For six months in 1966-7 he had built fireproof doors insulated with asbestos plates sawn and ground at the site. He had also used asbestos as an insulation material in plumbing work for one month.

In autumn 1982 the patient saw a doctor because of difficulty in breathing, and a radiograph taken in December that year showed a round opacity $4 \mathrm{~cm}$ in diameter in the central part of the right upper lobe; no abnormalities were observed in the peripheral lung fields. In February 1983 a thoracotomy was performed, and the surgeon reported fibrous plaques in the parietal pleura and a tumour in the right upper lobe, which was resected.

The resected upper lobe contained a central tumour $5 \mathrm{~cm}$ in diameter, histologically a small cell carcinoma of the intermediate cell type. ${ }^{13}$ At the periphery of the lobe, in connection with a scar, there was another tumour, $1 \mathrm{~cm}$ in diameter, histologically a well differentiated keratinising squamous cell carcinoma. ${ }^{13}$ The small cell carcinoma showed numerous cytoplasmic argyrophilic granules (Grimelius positive) but the squamous cell carcinoma did not. The peripheral lung tissue showed generalised peribronchiolar and perivascular fibrosis with large amounts of black dust in addition to many alveolar haemosiderin laden macrophages and abundant ferruginous bodies, at least ten per bronchiolus. Small birefringent crystals or sticks could be seen amid the black dust by polarising light. Peribronchiolar fibrosis extended from the nonrespiratory bronchioles to the level of the alveolar ducts, corresponding to grade 2 in severity and grade $\mathrm{C}$ in extent in the asbestosis evaluation scheme of Craighead et $a^{10}$ (fig 1). The histopathological diagnosis was evident asbestosis accompanied by heavy accumulations of undefined inorganic mixed dust and two primary carcinomas.

The dust particles analysed in the lung tissue were mostly minerals surrounded by lysosomes full of 


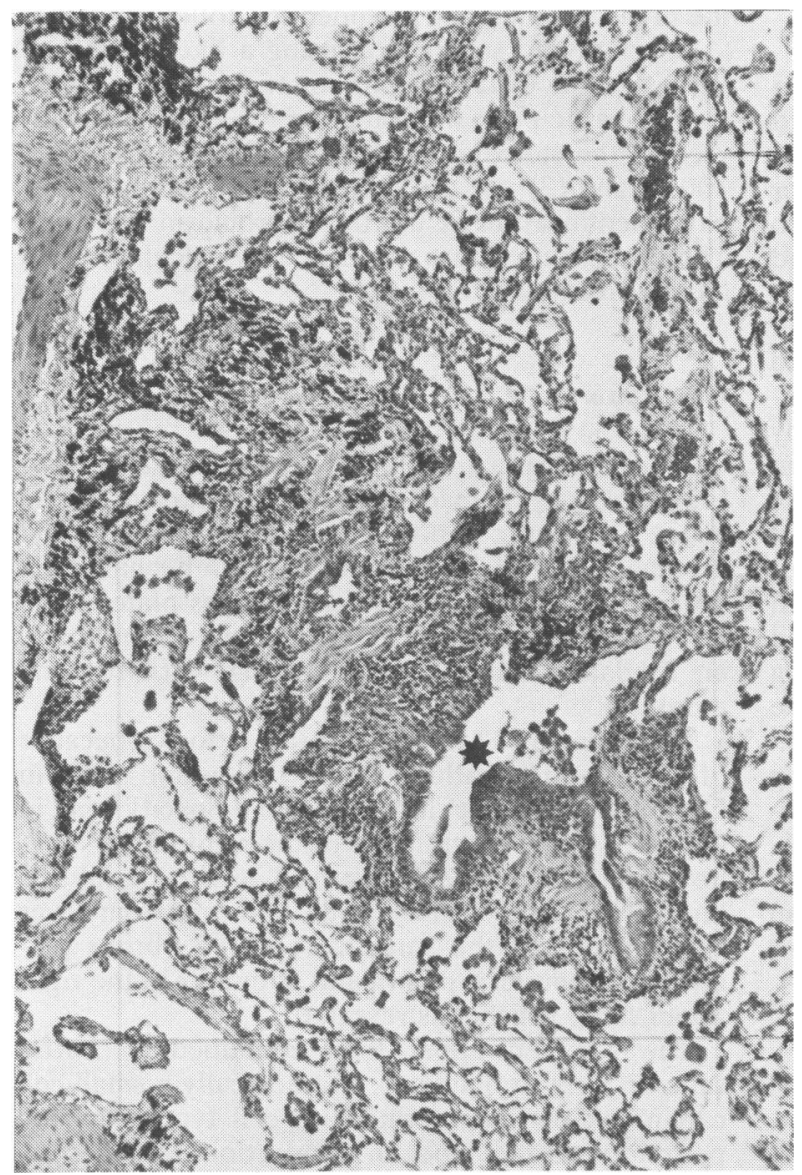

Fig 1 Light micrograph of peripheral lung tissue showing a respiratory bronchiole (asterisk) and slight fibrosis close to it. A considerable amount of black dust is seen in the fibrotic area.

(Haematoxylin and eosin $\times 221$.)

small haemosiderin granules containing iron (fig 2). The compositions and most probable origins of the minerals detected are shown in the table and fig 3 . Fourteen of the 16 particles analysed by the concentration ratio method were characterised as natural minerals and the remaining two as mullite, an artificial mineral used as a fire clay.

\section{Discussion}

To analyse inorganic pulmonary dust particles one can destroy the organic material chemically or physically and examine the mineral residues. ${ }^{14-18}$ These methods need relatively large amounts of material and are thus better suited to materials obtained at necropsy than to lung biopsies. Some minerals may also be altered during digestion of the organic material. ${ }^{171920}$ These methods do, however, offer a means of determining the total quantity of dust present. $^{16}$ Abraham and Burnett have recently developed a method for estimating pulmonary dust content in situ in tissue sections. ${ }^{21}$

The method we used here, $x$ ray microanalysis of the mineral particles present in the lung tissue specimens, ${ }^{22-25}$ is suitable for small biopsy specimens, as the material is not destroyed. It also allows examination of the morphology of the particle and its relations to the surrounding tissue. Quantitative energy dispersive $x$ ray spectroscopy, according to Cliff and Lorimer, is superior to qualitative methods for the characterisation of asbestos and other minerals. ${ }^{4}$ Pneumoconiosis is often caused by several types of mineral, which makes the interpretation of qualitative $x$ ray microanalyses difficult, as a large number of spectra from known minerals is needed for comparison. The 16 mineral particles studied in the present case originated from nine natural minerals and two artificial mullites.

Quantitative $x$ ray microanalysis with scanning transmission electron microscopy is laborious, how- 


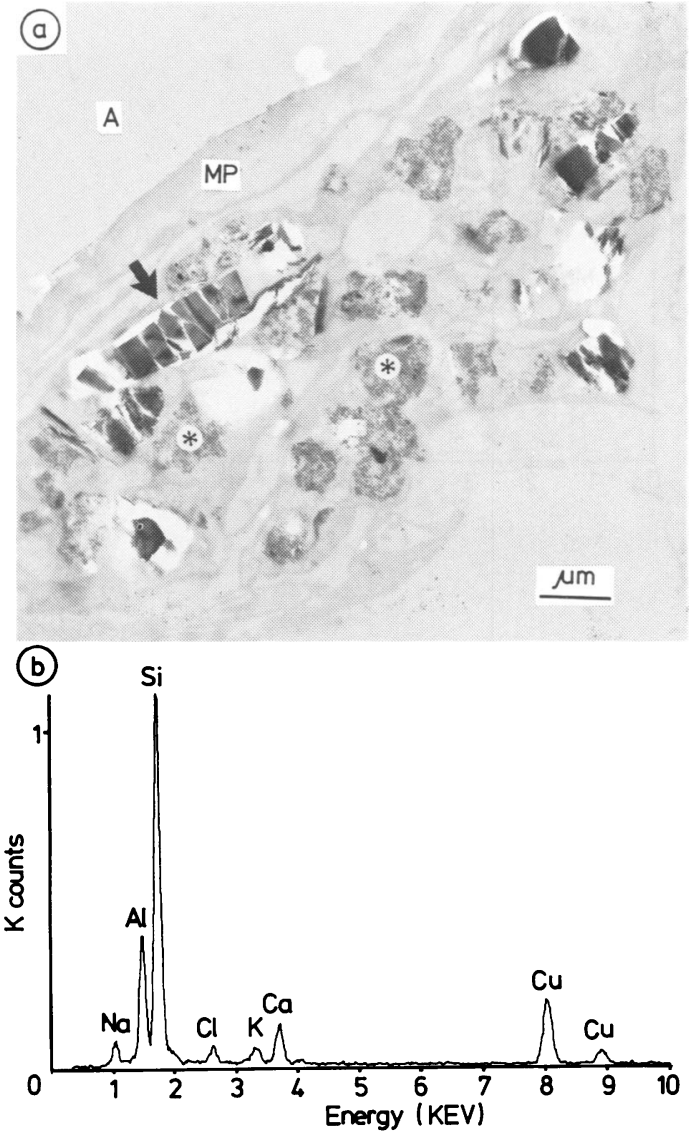

Fig 2 (a) Electron micrograph of an oligoclase particle (arrow) in a pulmonary interstitial macrophage. Cell also contains smaller dust particles and lysosomes filled with haemosiderin granules (asterisks). $M P=$ membranous pneumocyte. $A=$ alveolus. (Uranyl acetate $\times 6386$.) (b) Energy dispersive $x$ ray microanalysis spectrum of oligoclase with spikes of sodium, aluminum, silicon, potassium, and calcium. Chloride origins from preparation procedures and copper from supporting grid.

Oxides calculated from measured energy dispersive $x$ ray microanalysis spectra; minerals identified from the results of analysis and probable origin of minerals

\begin{tabular}{|c|c|c|c|c|c|c|c|c|c|c|}
\hline \multicolumn{8}{|c|}{ Oxides in weight percentage (normalised to $100 \%$ ) } & \multicolumn{2}{|l|}{ Mineral } & \multirow[t]{2}{*}{ Probable origin } \\
\hline $\mathrm{NaO}_{2}$ & $\mathrm{MgO}$ & $\mathrm{Al}_{2} \mathrm{O}_{3}$ & $\mathrm{SiO}_{2}$ & $\mathrm{~K}_{2} \mathrm{O}$ & $\mathrm{CaO}$ & $\mathrm{TiO}_{2}$ & $\overline{\mathrm{FeO}}$ & & & \\
\hline - & - & - & 100 & - & - & - & - & Quartz & & Sand \\
\hline 4.9 & - & $17 \cdot 0$ & $65 \cdot 8$ & $1 \cdot 0$ & $5 \cdot 7$ & - & $5 \cdot 6$ & Andesine & $\mathrm{NaA} I \mathrm{Si}_{3} \mathrm{O}_{8}-\mathrm{CaAl}_{2} \mathrm{Si}_{2} \mathrm{O}_{8}$ & Sand \\
\hline $7 \cdot 4$ & - & $22 \cdot 2$ & $63 \cdot 5$ & $1 \cdot 6$ & $5 \cdot 2$ & - & - & Oligoclase & $\mathrm{NaAlSi}{ }_{3}^{3} \mathrm{O}_{8}^{8}-\mathrm{CaAl}_{2} \mathrm{Si}_{2}^{2} \mathrm{O}_{8}^{8}$ & Sand \\
\hline $7 \cdot 5$ & - & $26 \cdot 6$ & $60 \cdot 0$ & 0.4 & $4 \cdot 3$ & - & $1 \cdot 2$ & & & \\
\hline - & - & $19 \cdot 1$ & $65 \cdot 6$ & $15 \cdot 3$ & - & - & - & Orthoclase & $\mathrm{KAISi}_{3} \mathrm{O}_{8}$ & Sand \\
\hline - & - & $19 \cdot 0$ & $64 \cdot 2$ & $15 \cdot 3$ & - & - & $1 \cdot 1$ & & & \\
\hline $1 \cdot 6$ & - & $18 \cdot 5$ & $67 \cdot 8$ & $11 \cdot 0$ & - & - & $1 \cdot 1$ & & & \\
\hline- & $26 \cdot 7$ & $7 \cdot 0$ & $61 \cdot 2$ & $2 \cdot 5$ & $\overline{1.4}$ & $\overline{-}$ & $2 \cdot 6$ & Anthophyllite & $(\mathrm{Mg}, \mathrm{Fe})_{7}\left[\mathrm{Si}_{8} \mathrm{O}_{22}\right](\mathrm{OH}, \mathrm{F})_{2}$ & Asbestos \\
\hline 二 & $\underline{31 \cdot 1}$ & $\overline{35} \cdot 5$ & 52.4 & $\overline{8} \cdot 8$ & $1 \cdot 4$ & $\overline{1 \cdot 3}$ & $\overline{2 \cdot 1}$ & Muscovite & $(\mathrm{OH}, \mathrm{F})$ & Sand \\
\hline - & $33 \cdot 5$ & - & $66 \cdot 2$ & - & - & - & 0.3 & Talc* & ${ }_{0}^{2}(\mathrm{OH})_{4}$ & Contaminant in \\
\hline - & $29 \cdot 0$ & $0 \cdot 8$ & $69 \cdot 0$ & - & - & - & $1 \cdot 3$ & & & asbestos \\
\hline - & $32 \cdot 1$ & - & $67 \cdot 1$ & - & - & - & $0 \cdot 8$ & Chrysotile* & $\mathrm{Mg}_{2}\left[\mathrm{Si}_{3} \mathrm{O}_{5}\right](\mathrm{OH})_{4}$ & Asbestos \\
\hline - & - & $32 \cdot 2$ & $36 \cdot 6$ & - & - & - & $31 \cdot 2$ & Almandine & $\mathrm{Fe}_{3} \mathrm{Al}{ }_{2}(\mathrm{Si}, \mathrm{Al})_{3} \mathrm{O}_{12}$ & Abrasive paper \\
\hline - & - & $40 \cdot 3$ & $58 \cdot 0$ & 0.6 & - & - & $1 \cdot 1$ & Mullite & & Fire clay \\
\hline - & $9 \cdot 7$ & $20 \cdot 0$ & $66 \cdot 5$ & - & - & - & $3 \cdot 9$ & & & \\
\hline
\end{tabular}

*See fig 3. 

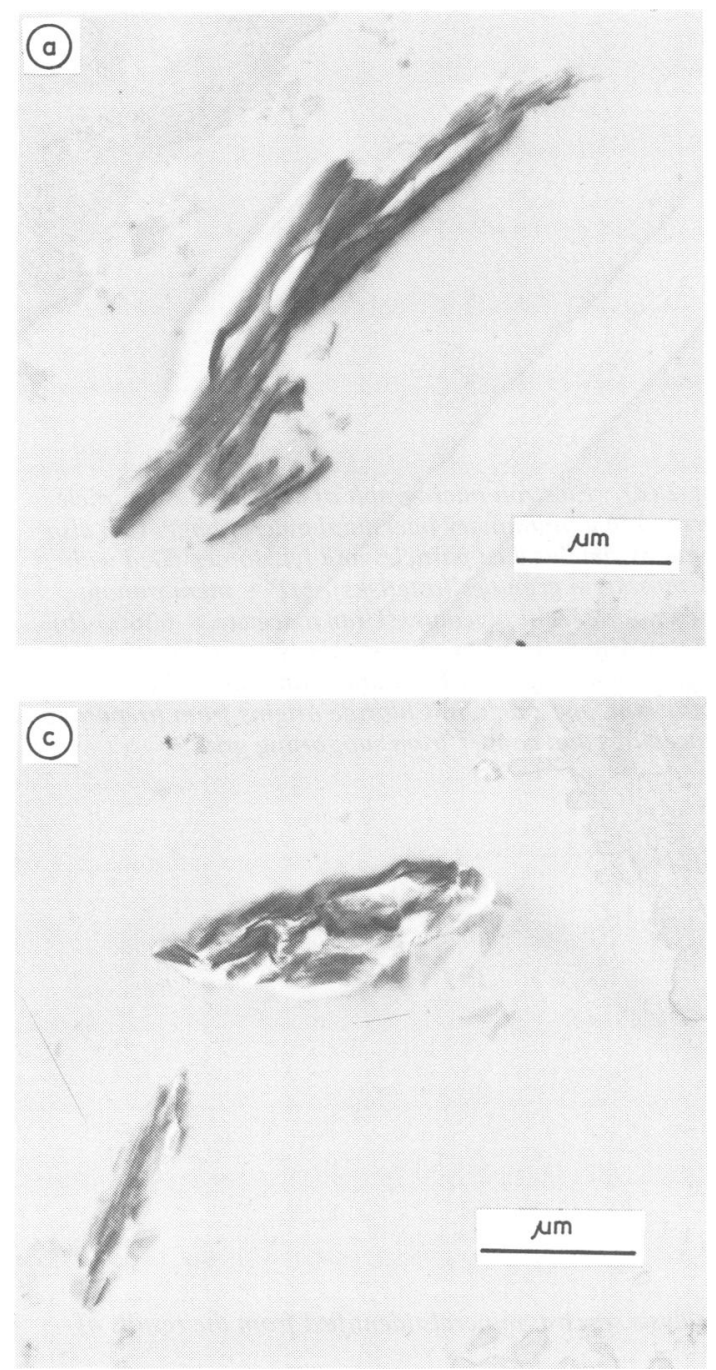

ever, and therefore only 20-40 spectra per case can be analysed within a reasonable time. This is a limitation, since the particles identified probably do not represent all the minerals present in the lung tissue. In addition, because of the thin foil criterion of Cliff and Lorimer, one can reliably analyse only particles of $1 \mu \mathrm{m}$ diameter or less, or larger particles that may be cut to a thickness of $1 \mu \mathrm{m}$ at most. Minerals can occur in lung tissue that are too large in particle size to be included in the analysis, although they could probably be reached by energy dispersive $x$ ray microanalysis using scanning electron microscopy and a peak to background method of quantitative analysis.

The results of the analysis for this patient enabled our geologist to calculate formulas for all but two of

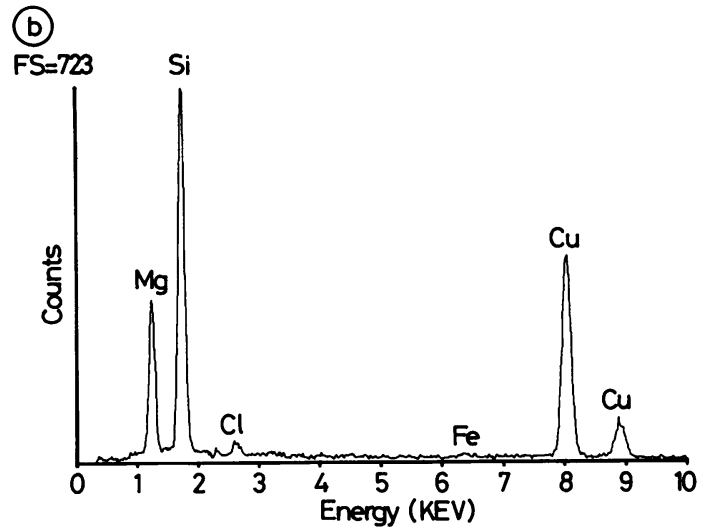

Fig 3 (a) Electron micrograph of a fibrillar alveolar particle showing shape of chrysotile. (Uranyl acetate $\times$ 14970.) (b) Energy dispersive $x$ ray microanalysis spectrum of particle in (a). Magnesium content is lower than expected in chrysotile, thus suiting better to talc. Because of magnesium depletion reported, fibres in (a) were assigned to chrysotile. (c) Electron micrograph of talc particles. Difference from shape of chrysotile is remarkable. (Uranyl acetate $\times 16086$.)

the minerals. These were identified as artificial mullites, which have no fixed stoichiometric formula. The morphology of the particle had to be used to distinguish talc from chrysotile asbestos, as some fibres with the appearance of chrysotile had a magnesium content lower than that of chrysotile, and thus the composition fitted better with talc. The fibres were assigned to chrysotile, however, since magnesium depletion from chrysotile has been reported in vitro ${ }^{20}$ and in living tissues. ${ }^{26}$ The most likely origins of the minerals detected in the resected lung specimen were compatible with the exposure history of the patient.

The association of exposure to asbestos with lung cancer, ${ }^{27}$ and also the synergistic effect of asbestos 
dust and cigarette smoking on the incidence of lung cancer, ${ }^{28}$ have been well known for a long time. Multiple primary tumours in asbestos workers have also been reported. ${ }^{29}$ Asbestos induced lung carcinomas either show no differences in cell type ${ }^{30}$ from general lung cancer series or only a slight predominance of adenocarcinomas. ${ }^{31}$ Our patient also had two separate tumours: a peripheral squamous cell carcinoma associated with a scar and a central small cell carcinoma with argyrophil granules.

In conclusion, quantitative $x$ ray microanalysis proved to be an effective tool for the reliable identification of individual mineral particles inhaled by the patient into his lungs. Although naturally it cannot tell us whether the tissue reaction the pathologist discovers is induced by this dust or not, it does provide a good opportunity for examining the relation between known inorganic dust and a certain tissue reaction.

Requests for reprints to: Sisko Anttila, MD, Department of Pathology, University of Oulu, Kajaanintie 52 D, SF-90220 Oulu 22, Finland.

\section{References}

' Churg A, Warnock ML, Green N. Analysis of the cores of ferruginous (asbestos) bodies from the general population. II. True asbestos bodies and pseudoasbestos bodies. Lab Invest 1979; 40:31-8.

${ }^{2}$ Champness PE, Cliff G, Lorimer GW. The identification of asbestos. J Microsc 1976; 108:231-49.

${ }^{3}$ Samudra AV. Optimum procedure for asbestos fibers identification from selected area electron diffraction patterns in a modern analytical electron microscope using tilted specimens. Scan Electron Microsc 1977; 1:385-92.

4 Cliff G, Lorimer GW. The quantitative analysis of thin specimens. J Microsc 1975; 103:203-7.

${ }^{5}$ Pooley FD. The identification of asbestos dust with an electron microscope microprobe analyser. Ann Occup Hyg 1975; 18:181-6.

- Lorimer GW. X-ray microanalysis in the TEM. In: Goringe MJ, ed. Electron microscopy and analysis 1981. Bristol: J W Arrowsmith Ltd, 1982:147-52.

${ }^{7}$ Malami C, Grassenbauer M. Identification of respirable asbestos fibres by quantitative $x$-ray microanalysis with a scanning transmission electron microscope (STEM). Fresenius Zeitschrift für Analytische Chemie 1982;311:1-6.

8 McDowell EM, Trump BF. Histologic fixatives suitable for diagnostic light and electron microscopy. Arch Pathol Lab Med 1976; 100:405-14.

' Grimelius L. The argyrophil reaction in islet cells of adult human pancreas studies with a new silver nitrate procedure. Acta Socio-Medica Scandinavica 1968;73:271-94.

${ }^{10}$ Craighead JE, Abraham JL, Churg A, et al. Asbestos-associated diseases. The pathology of asbestos-associated diseases of the lungs and pleural cavities: diagnostic criteria and proposed grading scheme. Arch Pathol Lab Med 1982;106:540-97.

" Goldstein JF, Costley JL, Lorimer GW, Reed SJB. Quantitative $x$-ray analysis in the electron microscope. Scan Electron Microse 1977;1:315-23.

${ }^{12}$ Barbi NC. Quantitative methods in biological $x$-ray microanalysis. Scan Electron Microsc 1979;II:659-72.

${ }^{13}$ International histological classification of tumours No 1. Histological typing of lung tumours. Geneva: World Health Organisation, 1981.

${ }^{14}$ Gross P, deTreville RTP, Cralley LJ, Davis JMG. Pulmonary ferruginous bodies. Development in response to filamentous dust and a method of isolation and concentration. Arch Pathol 1968;85:539-46.

is Smith MJ, Naylor B. A method for extracting ferruginous bodies from sputum and pulmonary tissue. Am J Clin Pathol 1972;58:250-4.

16 Ashcroft T, Heppleston AG. The optical and electron microscopical determination of pulmonary asbestos fibre concentration and its relation to the human pathological reaction. J Clin Pathol 1973;26:224-34.

17 Langer AM, Ashley R, Baden V, et al. Identification of asbestos in human tissues. JOM 1973;15:287-95.

${ }^{18}$ Rüttner JR, Spycher MA, Sticher H. The detection of etiologic agents in interstitial pulmonary fibrosis. Hum Pathol 1973;4:497-512.

19 Nagy B, Bates TF. Stability of chrysotile asbestos. American Mineral 1952;37:1055-9.

${ }^{20}$ Speil S, Leineweber JP. Asbestos minerals in modern technology. Environ Res 1969;2:166-208.

${ }^{21}$ Abraham JL, Burnett BR. Quantitative analysis of inorganic particulate burden in situ in tissue sections. Scan Electron Microsc 1983;11:681-96.

${ }^{22}$ Morgenroth K, Blaschke R, Schlake W. Energie dispersive x-ray analysis of semi-thin sections in the scanning transmission. Beiträge zur Pathologie 1973;150:406-11.

${ }^{23}$ Siegesmund KA, Funahashi A, Pintar K. Identification of metals in lung from a patient with interstitial pneumonia. Arch Environ Health 1974;28:345-9.

${ }^{24}$ Abraqam JL. Recent advances in pneumoconiosis: the pathologist's role in etiologic diagnosis. In: Thurlbeck WM, Abell MR, eds. The lung. Structure, function and disease. Baltimore: Williams \& Wilkins Company, 1978:96-137.

${ }^{25}$ Lapenas DJ, Davis GS, Gale PN, Brody AR. Mineral dusts as etiologic agents in pulmonary fibrosis: the diagnostic role of analytical scanning electron microscopy. Am J Clin Pathol 1982;78:701-6.

26 Jaurand MC, Bignon J, Sebastien P, Goni J. Leaching of chrysotile asbestos in human lungs. Correlation with in vitro studies using rabbit alveolar macrophages. Environ Res 1977; 14:245-54.

${ }^{27}$ Doll $\mathrm{R}$. Mortality from lung cancer in asbestos workers. $\mathrm{Br} \mathrm{J}$ Ind Med 1955; 12:81-6.

${ }^{28}$ Hammond EC, Selikoff IJ, Seidman H. Asbestos exposure, cigarette smoking and death rates. Annals of the New York Academy of Sciences 1979;330:473-90.

${ }^{29}$ Dohner VA, Beegle RG, Miller WT. Asbestos exposure and multiple primary tumours. Am Rev Respir Dis 1975; 112: 181-99.

${ }^{30}$ Kannerstein M, Churg J. Pathology of carcinoma of the lung associated with asbestos exposure. Cancer 1972;30:14-21.

31 Whitwell F, Newhouse ML, Bennett DR. A study of the histological cell types of lung cancer in workers suffering from asbestosis in the United Kingdom. Br J Ind Med 1974;31:298-303. 